\title{
Infectious diseases in the first year after kidney transplantation in Vietnamese: a single-center cohort study
}

\author{
Ho Trung Hieu', Bui Tien Sy ${ }^{2}$, Nguyen Thu $\mathrm{Ha}^{3}$ \\ 1Department of Nephrology, Urology, Transplantation, 108 Military Central Hospital, Hanoi, Vietnam
${ }^{2}$ Department of Microbiology, 108 Military Central Hospital, Hanoi, Vietnam
${ }^{3}$ Department of Nutrition, 108 Military Central Hospital, Hanoi, Vietnam
}

Background: Kidney recipients experience a high burden of infections throughout the first year post-transplantation, with opportunistic pathogens and predominance of viral and bacteria.

Methods: In this prospective study, all clinically relevant infections were identified by physicians in kidney transplant patients between December 2016 and June 2021 in 108 Military Central Hospital, Vietnam. The viral infections were identified by blood and urine samples. Among 87 kidney recipients, 71 patients with at least 12 months of follow-up were identified.

Results: Sixty-seven patients (94.4\%) suffered viral and/or bacterial infections during the first year post-transplantation. Bacteria were responsible for 27 infections (38.0\%) prevailing throughout the year, with $23.9 \%$ as urinary tract infection, $8.4 \%$ as respiratory pathogens, and $5.6 \%$ as digestive tract pathogens. Bacterial infections were highest in the first-month post-transplantation (22.5\%). Among 67 viral infections, BK and JC polyomavirus (62.0 and $56.3 \%$ ), cytomegalovirus (66.2\%), Epstein-Barr virus (12.7\%), herpes simplex virus (4.2\%), and both B19 and hepatitis C (2.8\%) in kidney transplant recipients. The prevalence of viral infection found via blood samples is lower than via urine samples $(77.5 \%$ and $87.3 \%$ ) over 12 months across all kidney recipients. The highest viral infection was found in the sixth month post-transplantation, $35.2 \%$ and $53.5 \%$ via blood and urine samples, respectively. Conclusions: The burden of post-transplant infections is high in the current study. Multiple methods should be used to identify infectious diseases after kidney transplantation.

Corresponding author: Nguyen Thu Ha

E-mail: nguyenthuha.dietitian@gmail.com

(c) The Korean Society for Transplantation

This is an Open Access article distributed under the terms of the Creative Commons Attribution Non-Commercial License (http://creativecommons.org/licenses/by-nc/4.0/) which permits unrestricted non-commercial use, distribution, and reproduction in any medium, provided the original work is properly cited. 